\title{
Pipeline stress analysis and load-bearing capacity analysis in the context of trenchless renovation of sewer networks
}

\author{
Roman Hurgin" and Nikita Bychkov \\ Moscow State University of Civil Engineering, Yaroslavskoe shosse, 26, Moscow, 129337, Russia
}

\begin{abstract}
Different methods and algorithms are used when conducting research on pipeline hydraulics and their strength calculation. However, processing of the received output is time-consuming and does not allow for expeditious decision on the necessary solution, which in turn leads to the change of the input parameters. The solution to this situation for the designer is to use an automated computer program. The benefits of this approach are the considerable decrease in length of time spent on analysis and ability to see alternatives, for example, change in diameter of the pipe, pipe wall thickness, material for filling the intertubular space and other parameters. In the following article we provide a description of the automated computer program used for scientific research.
\end{abstract}

\section{Introduction}

The international practice of sewer network operating shows that one of the most widespread renovation technique of old non-pressure pipe systems is pulling polymeric pipes through them as well as application of the inner protection coatings, for example, polymeric sleeves, to the inner surface of the dilapidated pipe systems. The building materials (pipes and protective coatings) used for renovation of old pipe systems should be considered a prime factor for achieving a proper defensive barrier between the transported liquid and the environment. In doing so, the pipe protective material should be resistant to periodic cleaning using water flow or scraping devices to remove slurry particles, biofilms, corrosion products and solid sludge [1-4].

However, in the practice of operating sewer networks we do not always achieve an expected degree of effectiveness. The problems that arise during the operation of sewerage systems renovated using polymeric pipes and sleeves can be caused by a number of factors, such as [5-11]:

- incorrect choice of the pipe or protective coating material for renovation of dilapidated pipe system (for example, failure to meet quality requirements of national building standards);

\footnotetext{
"Corresponding author: hurgin@mail.ru
} 
- lack of justification of the necessary pipe wall thickness (layer of protective coating) and strength calculations that ensure long-term and reliable operation of two-layer pipe system which in turn should hold the internal and external loads;

- lack of or inadequate attention to the securing the necessary conditions of hydraulic compatibility of old and new sections of renovated pipelines;

- failure to comply with rules concerning the technology of production in the course of laying and assembly of pipes (protective coatings) during the process of renovation as well as other requirements in place regulating conditions necessary for the application of thermal conductive paste.

\section{Materials and methods}

Based on the analysis of the problem of technical condition of old pipe systems and their operation after trenchless renovation using polymeric materials the objectives of this study are:

- to provide an overview and specific review of the factors destabilizing operation of non-pressure pipe systems, in particular, the Moscow sewerage network, on the basis of statistics on operation and repair of separate sections;

- to research the possibility of employing the method of pulling through and installing polymeric pipes inside the old pipelines as standard trenchless technology, in accordance with the following the algorithm: strengthening of the pipelines - pulling through new pipes inside the pipeline - pipes fixing.

In the process of setting research objectives, it was noted that the more prospective materials used to correct the defects of the old pipelines (cracks, open splices, etc) are polymeric materials, in particular, pipes and protective coatings. The use of polymeric pipes allows for restoration of strength characteristics of old pipelines and for creation of suitable conditions for transportation of sewage water with virtually zero sedimentation as well as for maintaining hydraulic characteristics of the flow due to the reduced surface roughness.

In the process of reconstruction of non-pressure pipelines composed of cast iron, asbestos-cement, reinforced concrete, ceramics and bricks, preliminary evaluation of the conditional operational status of the section of repaired pipe should be carried out. The results should conform to the following category:

- conditional operational status \#1, i.e. two-layer construction operates as a whole in the conditions when the renovated pipeline has minor defects (for example, deformation, seal failures);

$$
R^{*} \geq \sigma_{n p}
$$

Value $R^{*}$ is calculated according to formula:

$$
R^{*}=k_{1} \cdot R_{H} \cdot k_{y} \cdot k_{c}=2.16 \mathrm{MPa}
$$

where $k_{l}$ is the service factor, 0,$8 ; R_{u}$ is characteristic continuous resistance of the material of the pipe wall, $M P a$ (if operating for 50 years and temperature $20{ }^{\circ} \mathrm{C} R_{H}=5 \mathrm{MPa}$ ); $k_{y}$ is condition load effect factor, $k_{y}=0.6 ; k_{c}$ is joint strength factor, $k_{c}=0.9$;

- conditional operational status \#2, i.e. when the pipeline that is being renovated loses leak tightness whilst maintaining its load-bearing capacity;

- conditional operational status \#3, i.e. when the pipeline that is being renovated has no load-bearing capacity.

On the basis of the collected information we reach a provisional conclusion concerning the advisability and feasibility of application of polymeric pipes. The use of automated computer program is of great assistance when it comes down to strength calculations of the 
renovated pipe system (old pipeline + cement + polymeric pipeline) [12-13]. The program allows the user to make a strength calculation of the multilayered pipe construction that is formed after trenchless repair of the old pipeline by pulling a polymeric pipe through it and filling the intertubular space. The dialog box of the program is presented in Fig. 1

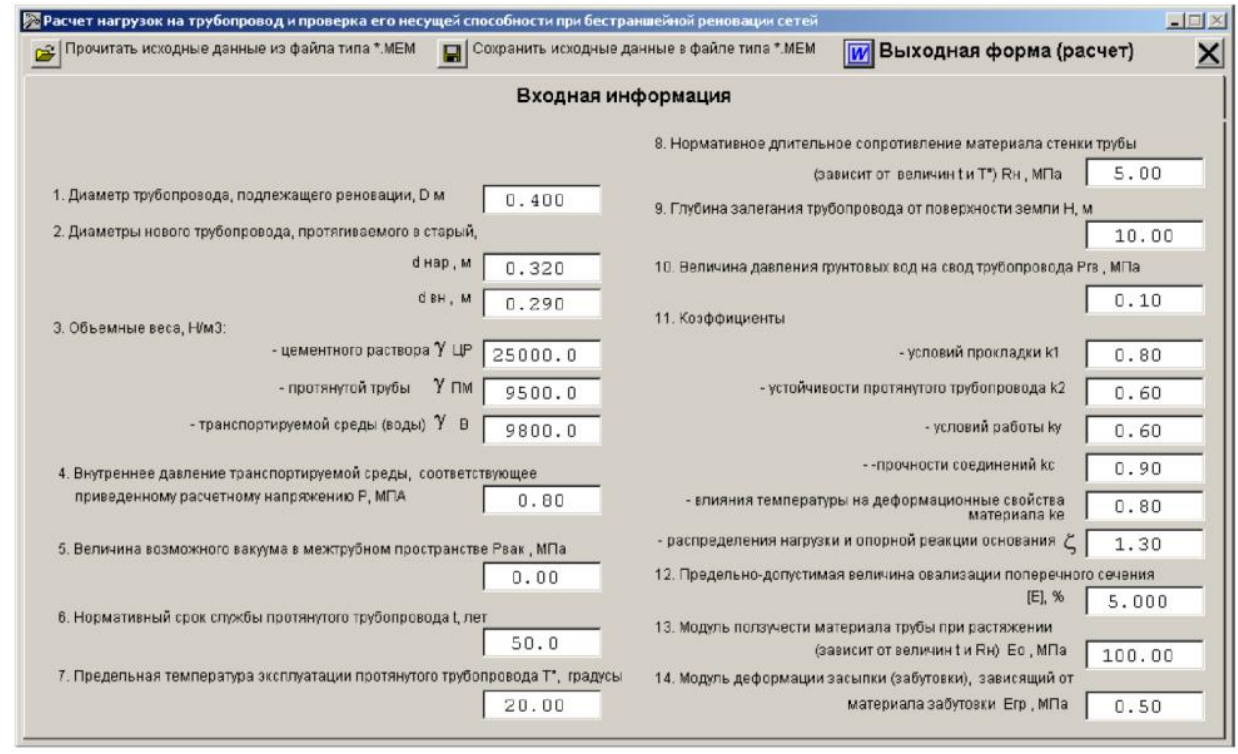

Fig. 1. Dialog box of the program (in Russian).

Caption: Pipeline stress analysis and load-bearing capacity analysis in the context of renovation of trenchless drainage systems

$\square$ Read the initial data from file *.MEM

$\square$ Save the initial data in file *.MEM

$\square$ Output data (analysis)

Input data

1. Diameter of the pipeline in need of renovation $\mathrm{D}, \mathrm{m}$

2. Diameter of the new pipeline intended to be put through the old pipeline, dout, $\mathrm{m}, \mathrm{din}, \mathrm{m}$

3. Volume weight, $\mathrm{n} / \mathrm{m}^{3}$ : - cement - pipeline - fluid (water)

4. Internal pressure of the transported fluid corresponding to the set stress design $\mathrm{P}, \mathrm{MPa}$

5. Size of the possible vacuum in the intertubular space $\mathrm{P}_{\text {vac }}, \mathrm{MPa}$

6. Nominal working life of a pipeline $t$, years

7. Temperature limit for the operation of the pipeline

8. Characteristic continuous resistance of the material of the pipe wall (depending on $t$ and $T$ values) $\mathrm{R}_{\mathrm{n}}, \mathrm{MPa}$

9. The depth of laying the pipeline measured starting from the surface of the earth $\mathrm{H}, \mathrm{m}$

10. The pressure of groundwater on the top of the pipeline $\mathrm{P}_{\mathrm{gw}}, \mathrm{MPa}$

11. Factors - service factor: $\mathrm{k}_{1}$ - pipeline resistance, $\mathrm{k}_{2}$ - condition load effect factor, $\mathrm{k}_{\mathrm{y}}$ - joint strength factor, $\mathrm{k}_{\mathrm{c}}$ - temperature effect on deformation properties of materials, $\mathrm{k}_{\mathrm{e}}-$ load distribution and bearing reaction factor.

12. Maximum permissible deformation of the cross section [E], \%

13. Material's creep modulus for pipes (depending on $t$ and $R_{H}$ values) $\mathrm{E}_{\mathrm{o}}, \mathrm{MPa}$

14. Filling's deformation modulus (depending on filling material) $\mathrm{Egr}, \mathrm{MPa}$

In the field "Input data", the user has to enter values in all 14 positions (Fig. 1). After that the data is saved. For the purposes of automated calculations and receiving the results there is an "Output form (analysis)" tab. If you click this tab you will receive all input and output data (analysis). To print the received data, you open a file and press print button. 


\section{Results and discussion}

An example of the analysis of the pipe system after repairing a steel pipe with the internal diameter $\mathrm{D}=0.4$ meters using a polymeric pipe with diameters $\mathrm{d}_{\text {out }}=0.32 \mathrm{~m}$ and $\mathrm{d}_{\text {int }}=0.29$ $\mathrm{m}$. The input data corresponds to the data presented in the dialog box (Fig. 1).

Results of the work of the program are presented in the printout (without input data).

\section{OUTPUT FORM}

1. Load-bearing analysis of the construction internal pressure strength (condition I)

Pressure strength is ensured: $1.62 \mathrm{MPa}>\mathrm{P}=0.80 \mathrm{MPa}$

2. Load-bearing analysis of the construction on the condition of non-exceeding of maximum permissible deformation of the cross section of the pipeline (condition II)

Pipeline rigidity $\mathrm{Pl}$ in $\mathrm{n} / \mathrm{m}^{2}: 132846.78$

Pipeline rigidity $\mathrm{Pl}^{*}$ in $\mathrm{MPa}: 0.132847$

Coefficient that takes account of combined effect of bearing reaction and internal pressure: 0.1389

A. Load for the proportionate filling of the intertubular space on the condition of absence of water in pipe that is intended to be pulled through Ppr $1, n / \mathrm{m}^{2}:-1383.28$

Relative deformation of the vertical diameter of the pipeline $E_{1}, \%: 0.1469$;

(Deformation within normal parameters [E], \%: 5.0000)

$B$. Load for the proportionate filling of the intertubular space on the condition of presence of water in pipe that is intended to be pulled through $\mathrm{Ppr} 2, \mathrm{~N} / \mathrm{m}^{2}$ : -647.54

Relative deformation of the vertical diameter of the pipeline $\mathrm{E}_{2}, \%: 0.0687$;

(Deformation within normal parameters [E], \%: 5.0000)

C. Load for the disproportionate filling of the intertubular space on the condition of absence of water in pipe that is intended to be pulled through Ppr 3, N/m $\mathrm{m}^{2}:+1454.91$

Horizontal pressure force component during filling $\mathrm{P}_{\mathrm{x} 3}, \mathrm{~N} / \mathrm{m}^{2}: 1280.00$

Vertical pressure force component during filling $\mathrm{P}_{\mathrm{z} 3}, \mathrm{~N} / \mathrm{m}^{2}:-691.64$

Tangent of angle of inclination of net pressure force $\operatorname{tg} \alpha_{3}: 0.54$

Angle of inclination to the horizon of net pressure force $\alpha_{3}: 28.38^{\circ}$

Relative deformation of the vertical diameter of the pipeline $\mathrm{E}_{3}, \%: 0.1545$

(Deformation within normal parameters [E], \%: 5.0000)

D. Load for the disproportionate filling of the intertubular space on the condition of presence of water in pipe that is intended to be pulled through $\mathrm{Ppr} 4, \mathrm{~N} / \mathrm{m}^{2}:+1280.76$

Vertical pressure force component of water on the inner cylindrical surface of the pipe that is intended to be pulled through $\mathrm{P}_{\mathrm{B}}, N / m: 1280.00$

Horizontal pressure force component during filling $\mathrm{P}_{\times 3}, N / m: 1280.00$

Vertical pressure force component during filling $\mathrm{P}_{\mathrm{z} 3}, \mathrm{~N} / \mathrm{m}$ : -691.64

Tangent of angle of inclination of net pressure force tg $\alpha_{4}: 1.12$

Angle of inclination to the horizon of net pressure force $\alpha_{4}: 48.12^{\circ}$

Relative deformation of the vertical diameter of the pipeline $\mathrm{E}_{4}, \%$ : 0.1360 ;

(Deformation within normal parameters [E], \%: 5.0000)

3. Load-bearing analysis of the construction resistance of the round cross section of the pipe that is intended to be pulled through (condition III)

A. Uniform radial pressure during proportionate filling on the condition of absence of water in pipe that is intended to be pulled through P1, MPa: +0.163

Resistance ensured

$B$. Uniform radial pressure during proportionate filling on the condition of presence of water in pipe that is intended to be pulled through P2, MPa: +0.164

Resistance ensured 
C. Uniform radial pressure during disproportionate filling on the condition of absence of water in pipe that is intended to be pulled through P3, MPa: +0.1702

Resistance ensured

D. Uniform radial pressure during disproportionate filling on the condition of presence of water in pipe that is intended to be pulled through P4, MPa: +0.1701

Resistance ensured

According to results of computer simulation of the process of filling the intertubular space, the influence of several factors on the strength characteristics of the pipe structure were defined: the specific weight of building mortars, the pressure of groundwater on the pipeline, the method of intertubular space filling and the presence or absence of water in the pipeline.

\section{Conclusions}

Three-layered construction which consists of a repairable steel pipeline with polymeric pipes pulled through it and cement in the intertubular space, according to all (I, II, III) conditions of the automated analysis can be classified as having load-bearing capacity.

Automated computer program was developed to determine optimal parameters of any three-layered construction for subsequent effective and trouble-free operation in autonomous regime. The initial data lists diameters of old pipelines and new polymeric pipes intended to pass through the old ones, depth of laying the pipelines and ground water levels as well as specific weight of building mixes.

\section{References}

1. M. Najafi, Trenchless technology piping: Installation and Inspection (Reston, VA: McGraw-Hill Professional, 2010)

2. A. Zwierzchowska, Technologie bezwykopowej budowy sieci gazowych, wodociagowych i kanalizacyjnych (Politechnika swietokrzyska, 2006)

3. M.A. Somov. M.G. Zhurba, Water supply. Vol. 1. Systems of water withdrawal, supply and distribution (ASV. Moscow, 2008)

4. S.V. Khramenkov, Strategies of modernization of water supply systems (Stroyizdat. Moscow, 2005)

5. V. Orlov, S Zotkin, I. Dezhina, I. Zotkina, MATEC Web of Conferences 117, 00185 (2017)

6. V. Orlov, S. Zotkin, International Scientific Conference Energy Management of Municipal Transportation Facilities and Transport EMMFT 2017, 689-699 (2017)

7. V. Orlov, I. Averkeev, A. Pelipenko, International Scientific Conference Energy Management of Municipal Transportation Facilities and Transport EMMFT 2017, 392-401 (2017)

8. V. Orlov, MATEC Web Conf. 144, 02017 (2018)

9. V.A. Orlov, Pipelines. Automated maintenance of projects (LAN, St. Petersburg, 2015)

10. L.G. Zaichenko, N. V. Sorokina, O. V. Chomoniy, Donbass Nat. Acad. of Civil Eng. and Arch. Newsletter 2, 143-147 (2009)

11. B.B. Rajani, Y. Kleiner, Urban Water 3, 151-164 (2001)

12. S. Govindan, T. Walski, D. Cooke, CAD and graphics 4, 36-38 (2009)

13. D.A. Borisov, CAD and graphics 5, 64-68 (2009) 